
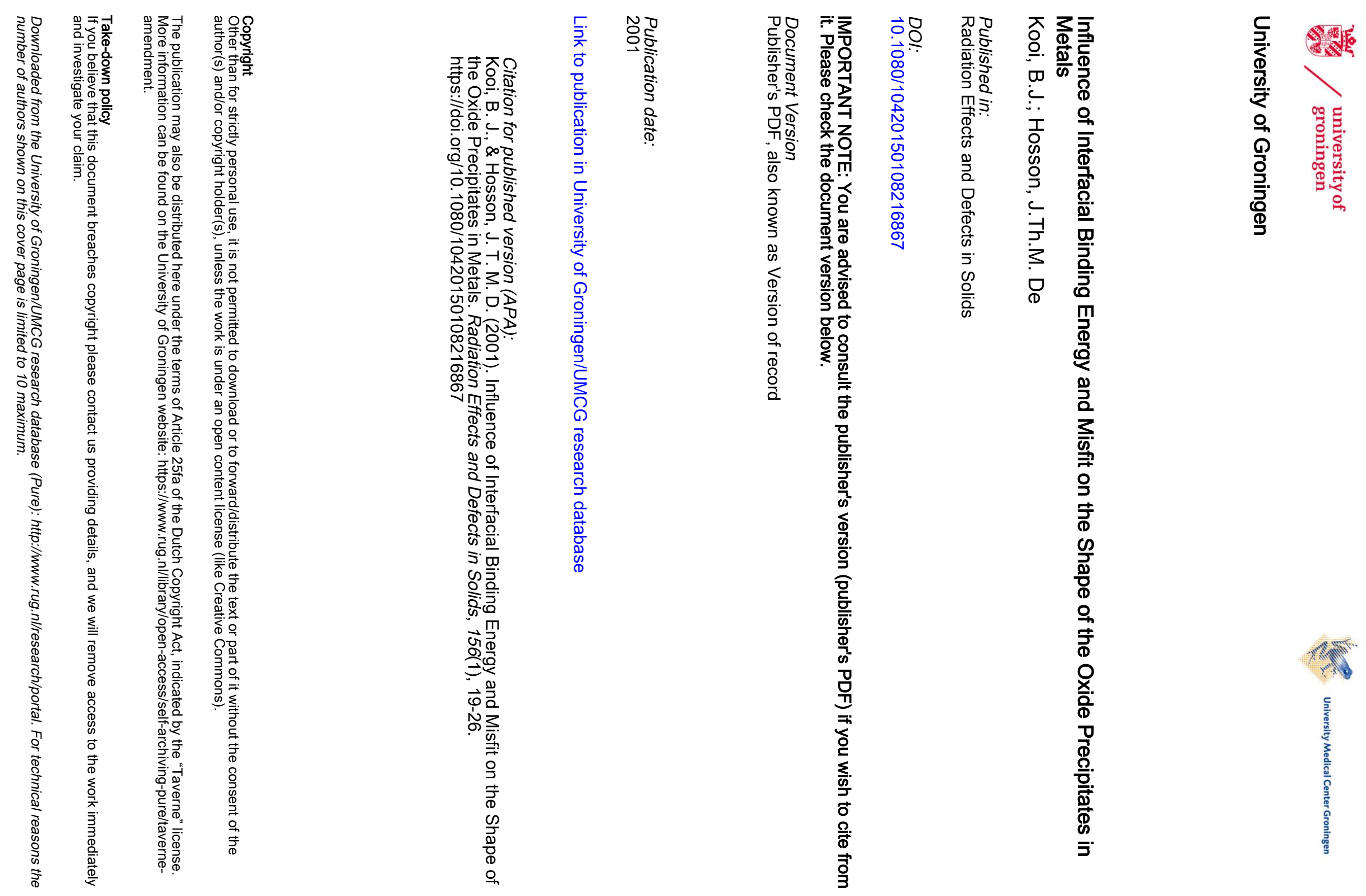


\title{
INFLUENCE OF INTERFACIAL BINDING ENERGY AND MISFIT ON THE SHAPE OF THE OXIDE PRECIPITATES IN METALS
}

\author{
B. J. KOOI and J. Th. M. De HOSSON* \\ Department of Applied Physics, Materials Science Centre and Netherlands \\ Institute for Metals Research, University of Groningen, Nijenborgh 4, \\ 9747 AG Groningen, The Netherlands
}

(Received 7 April 2000; In final form 30 July 2000)

\begin{abstract}
Transmission electron microscopy revealed $\mathrm{Mn}_{3} \mathrm{O}_{4}$ precipitates with two types of dominant shapes in $\mathrm{Pd}-3$ at. $\% \mathrm{Mn}$ that was internally oxidized in air at $1000^{\circ} \mathrm{C}$. One type is octahedrally shaped and bounded by $\{111\}$ planes of the $\mathrm{Mn}_{3} \mathrm{O}_{4}$. These observations were compared with earlier observations in the $\mathrm{Ag} / \mathrm{Mn}_{3} \mathrm{O}_{4}$ system. The octahedrons show a relatively larger (002) truncation in $\mathrm{Pd}$ than in $\mathrm{Ag}$. Further, the second type of precipitate shape, comprising about $\frac{1}{3}$ of all the precipitates in $\mathrm{Pd}$, was not observed in $\mathrm{Ag}$. It corresponds to a plate-like structure. HRTEM observations revealed the presence of a square misfit dislocation network with line direction $\langle 110\rangle$ and Burgers vector $\frac{1}{2}(110\rangle$ at these interfaces with $(002) \mathrm{Mn}_{3} \mathrm{O}_{4} / /\{200\} \mathrm{Pd}$. The general conclusion of the present analysis is (i) anisotropy in the interface energy for oxide precipitates in a metal matrix is substantial due to the ionic nature of the oxide, giving well defined shapes assaciated with the Wulff construction, (ii) the influence of misfit energy on the precipitate shape as bounded by semi-coherent interfaces is important only if sufficient anisotropy in the mismatch is present and if the matrix is sufficiently stiff, and (iii) the stronger coupling strength due to electronic binding effects across the interface in $\mathrm{Pd}$ compared to $\mathrm{Ag}$ is responsible for the formation of the dislocation network structures at larger misfit.
\end{abstract}

Keywords: Transmission electron microscopy; Composites; Interface

\section{INTRODUCTION}

The equilibrium shape of small inclusions (specified by the orientation relation (OR) together with interface orientations (IOs)) is determined by both the interfacial energy and strain energy. In the absence of strain, a con-

* Corresponding author. E-mail: hossonj@phys.rug.nl 
struction analogous to Wulff $[1,2]$, based on a polar plot of interface energy as a function of interface normal, provides uniquely the equilibrium shape of the precipitate [3]. Depending on the magnitude of the stress/ strain, the elastic energy can become appreciable and result in deviations of the equilibrium shape associated with the Wulff construction. In some systems, strain can be the dominant factor controlling the shape. Such systems can be found in the class of coherent metallic inclusions in a metal matrix in the presence of anisotropic strains. Then, the equilibrium shape can be predicted by approaches based on minimization of elastic-strain energy. In our previous work, the influence of the tetragonality on the precipitate shape and interface structure, i.e. particularly misfit-dislocation structure at the interfaces, of $\mathrm{Mn}_{3} \mathrm{O}_{4}$ precipitates in an $\mathrm{Ag}$ or $\mathrm{Cu}$ matrix was addressed [4-7]. For the investigations presented in this paper, the $\mathrm{Ag}$ (or $\mathrm{Cu}$ ) matrix was replaced by a $\mathrm{Pd}$ matrix. It will be shown that a comparison of these different systems gives important clues about the balance in the interfacial-binding energy and the misfit energy in determining the stability of (semi-coherent) metal/oxide interfaces.

\section{EXPERIMENTAL}

An alloy of Pd containing 3 atomic percent $\mathrm{Mn}$ starting from the pure constituents $(99.99 \%$ by weight) was prepared in an arc furnace. The button was homogenized for 5 days at a temperature of $850^{\circ} \mathrm{C}$ in an evacuated quartz tube. Subsequently, it was cold rolled from $5 \mathrm{~mm}$ down to $0.3 \mathrm{~mm}$. Manganese-oxide precipitates within $\mathrm{Pd}$ were obtained by oxidizing the alloy in air at $1000^{\circ} \mathrm{C}$ for times ranging between 2 and 10 days. The alloy oxidized for 2 days was also annealed for 1 week in an evacuated quartz tube at $1000^{\circ} \mathrm{C}$ in order to allow equilibration to occur.

Samples for (HR)TEM investigation were obtained by NdYag-laser cutting $3 \mathrm{~mm}$ discs from the $0.3 \mathrm{~mm}$ foil and by grinding, dimpling (Gatan model 656) and ion milling (Gatan PIPS model 691). For (HR)TEM a JEOL $4000 \mathrm{EX} / \mathrm{II}$ operating at $400 \mathrm{kV}$ was used (spherical aberration coefficient $0.97 \pm 0.02 \mathrm{~mm}$, defocus spread $7.8 \pm 1.4 \mathrm{~nm}$ and beam semiconvergence angle $0.8 \mathrm{mrad}$ ). 


\section{RESULTS}

Figure 1 shows a bright-field TEM image of an $\mathrm{Mn}_{3} \mathrm{O}_{4}$ precipitate in $\mathrm{Pd}$ as viewed along their common $\langle 110\rangle$ direction together with the corresponding SAED (selected area electron diffraction) pattern. The $\mathrm{Mn}_{3} \mathrm{O}_{4}$ precipitate was found to be bounded by 2 pairs of edge-on $\{111\}$ and one pair of edge-on (002) planes. Hence, the $\mathrm{Mn}_{3} \mathrm{O}_{4}$ has its long c-axis in the plane of projection. The SAED pattern shows that the $\{111\}$ of $\mathrm{Mn}_{3} \mathrm{O}_{4}$ are aligned parallel to the $\{111\}$ of Pd for only one pair of facets. For the other pair of $\{111\}$ facets, a tilt of $7.6^{\circ}$ around the $\langle 110\rangle$ viewing direction is present in-between the $\{111\}$ of $\mathrm{Pd}$ and $\mathrm{Mn}_{3} \mathrm{O}_{4}$. In-between the (002) of $\mathrm{Mn}_{3} \mathrm{O}_{4}$ and $\mathrm{Pd}$ a tilt of $3.8^{\circ}$ occurs, see SAED patterns in Figures 1 and 2. All these observations for $\mathrm{Mn}_{3} \mathrm{O}_{4}$ octahedrons in Pd are exactly similar to the observations for $\mathrm{Mn}_{3} \mathrm{O}_{4}$ octahedrons in $\mathrm{Ag}$. However, two important differences occur: (i) the $\mathrm{Mn}_{3} \mathrm{O}_{4}$ are about a factor 10 larger in $\mathrm{Pd}$ than in $\mathrm{Ag}$ and (ii) the (002) truncation of the octahedrons is substantial in $\mathrm{Pd}$ (see Fig. 1) and not in $\mathrm{Ag}$. In fact, truncation in $\mathrm{Ag}$ only becomes present after annealing in vacuo. The larger size of $\mathrm{Mn}_{3} \mathrm{O}_{4}$ precipitates in Pd compared to $\mathrm{Ag}$ is caused by the much lower oxygen permeability $\left(\mathrm{c}_{O} \mathrm{D}_{\mathrm{O}}\right.$ with $c_{O}$ the solubility and $D_{O}$ the diffusion coefficient of oxygen in the metal matrix) in Pd than in Ag. Besides the octahedron-shaped precipitates, which comprise about $2 / 3$ of all the precipitates, plate-like shaped precipitates were observed, comprising the rest of the precipitates. When viewing along $\mathrm{Pd}\langle 110\rangle$ direction, the plates were observed to lie along the $\mathrm{Mn}_{3} \mathrm{O}_{4}$ $\langle 110\rangle$ direction with edge-on interfaces as shown in Figure 2 together with the corresponding SAED pattern.

\section{DISCUSSION}

$\mathrm{Mn}_{3} \mathrm{O}_{4}$ precipitates in fcc metal matrices become interesting because a strong anisotropy component in misfit is added. The oxygen sublattice of $\mathrm{Mn}_{3} \mathrm{O}_{4}$ is fct with a c-axis $15.7 \%$ longer than its a-axis. Therefore, it corresponds to a tetragonal distortion of the fcc $\mathrm{O}$ sublattice of the $\mathrm{NaCl}$-type oxides. The a-axis of the fct $\mathrm{O}$ sublattice of $\mathrm{Mn}_{3} \mathrm{O}_{4}$ is near to or slightly larger than the lattice constant of most of the fcc metals, whereas the c-axis is substantially larger. Hence, the expected shape of the $\mathrm{Mn}_{3} \mathrm{O}_{4}$ precipitates in these fcc metals, complying to minimum misfit on the inter- 

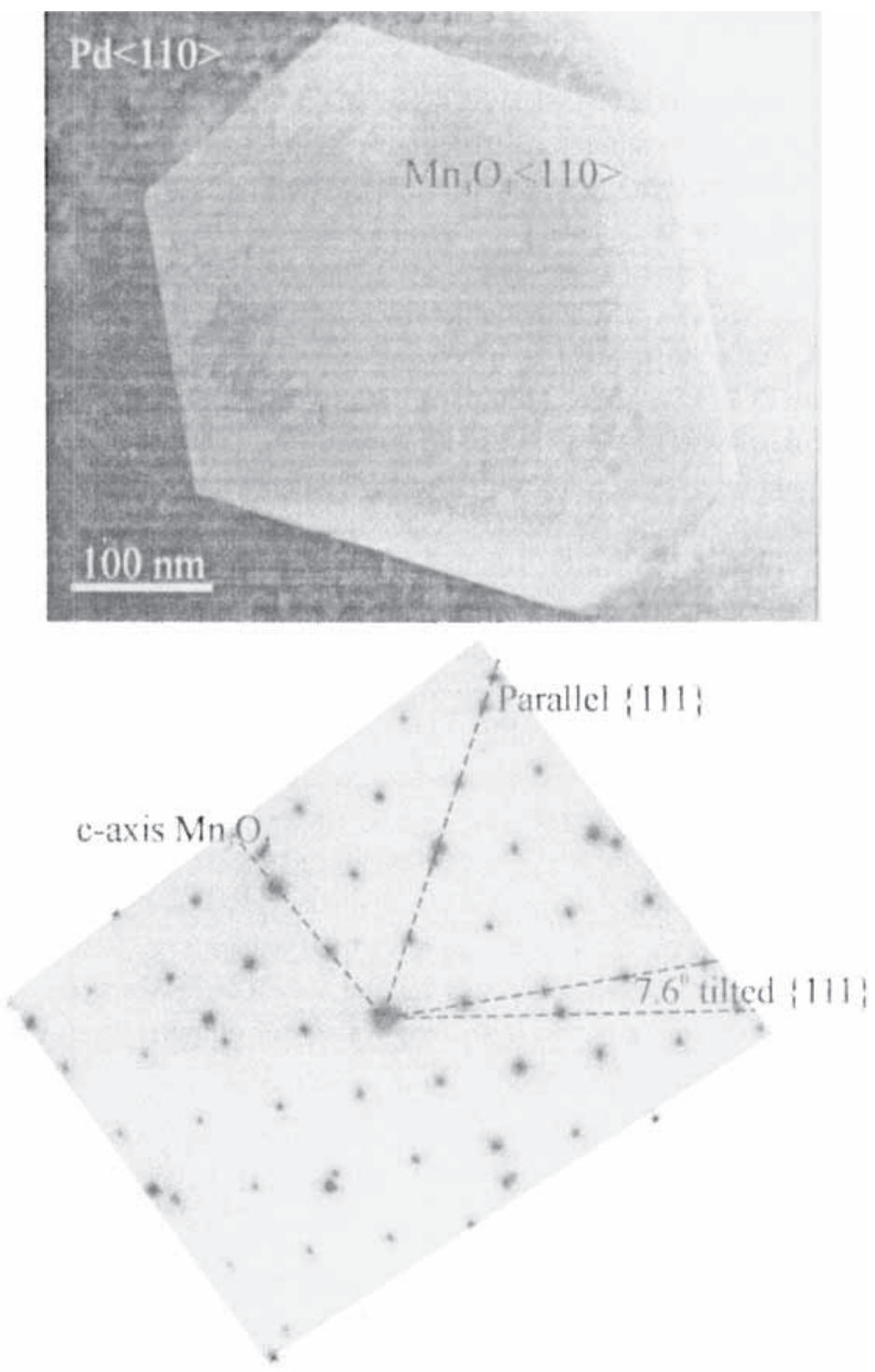

FIGURE I Bright-field TEM image and corresponding selected-area electron diffraction pattern of an $(002)$ truncated octahedrally shaped $\mathrm{Mn}_{3} \mathrm{O}_{4}$ precipitate in $\mathrm{Pd}$ as viewed along their common $\langle 110\rangle$ axis (note that this is the only common direction for $\mathrm{Mn}_{3} \mathrm{O}_{4}$ and $\mathrm{Pd}$ ). For one pair of facets, the $\{111\}$ of $\mathrm{Mn}_{3} \mathrm{O}_{4}$ and $\mathrm{Pd}$ are aligned parallel and then for the other pair of facets their $\{111\}$ planes show a muttal tilt of $7.6^{\circ}$ (where the tilt axis is parallel to the $\langle 110\rangle$ viewing direction). 

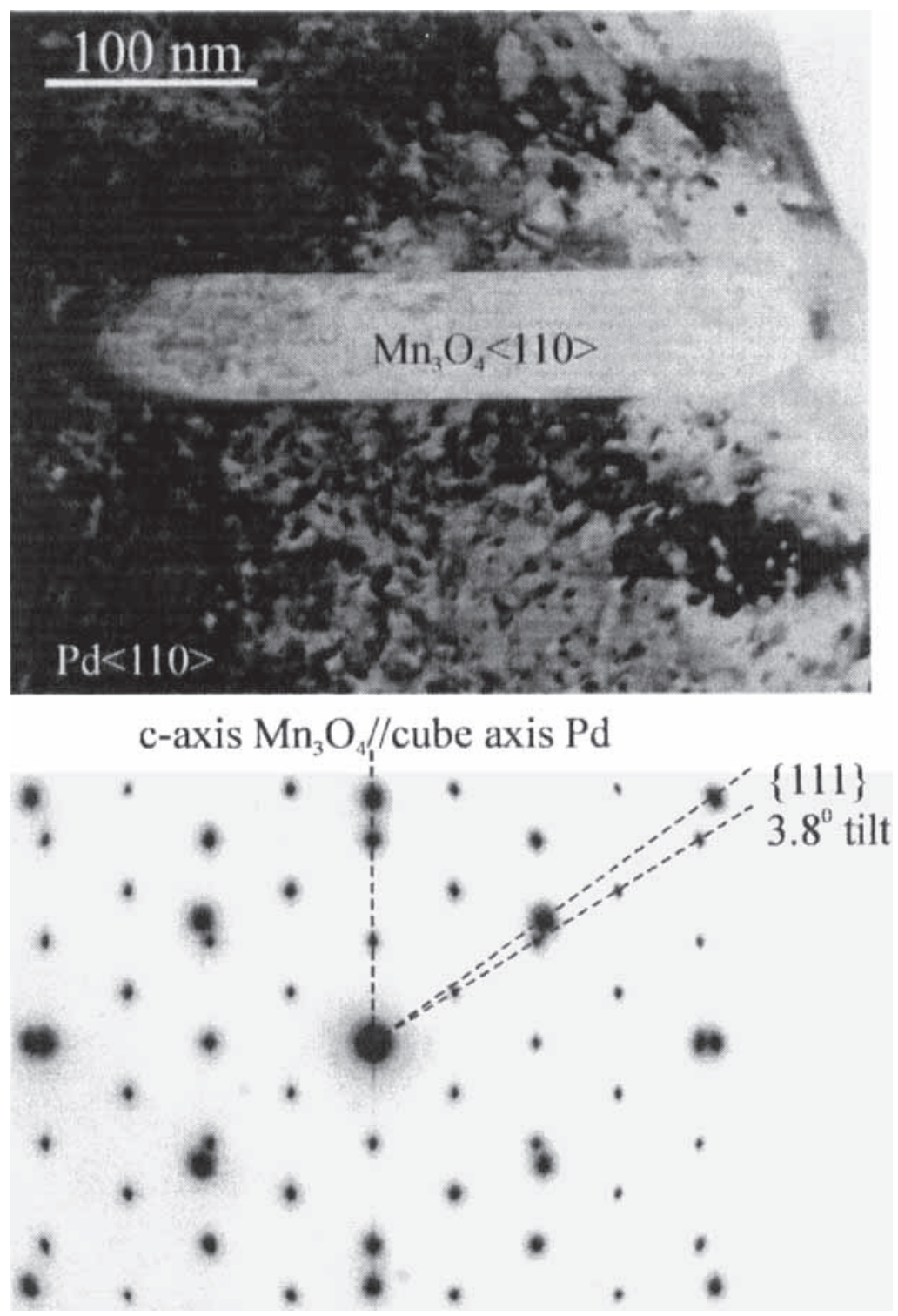

FIGURE 2 Bright-field TEM image and corresponding SAED pattern of a plate-shaped $\mathrm{Mn}_{3} \mathrm{O}_{4}$ precipitate in $\mathrm{Pd}$ as viewed along their common $\langle 110\rangle$ axis. For the dominant interface of the plate, the (002) of $\mathrm{Mn}_{3} \mathrm{O}_{4}$ is parallel to a cube plane of $\mathrm{Pd}$. 
faces, are plates with the c-axis as habit-plane normal. So, an interesting competition between the interfacial binding energy that favours the $\{111\}$ type interfaces and the misfit energy that favours the (002) facets will occur for the $\mathrm{Mn}_{3} \mathrm{O}_{4}$ precipitates in fcc metals. Note that misfit energy in the present sense does not refer to the strain energy of coherent inclusions that acts throughout the volume of the particle and part of the surrounding matrix, but to the network of misfit dislocations which have largely canceled the long-range stresses. Misfit between precipitate and matrix now does not act on the volume of the precipitate, but on a localized region near the interfaces. In this case, the influence of the mismatch in principle is an integral part of the interfacial energy. However, in order to make our point clear in the present discussion we have to make a distinction with the interfacial energy that is present in the absence of strain according to the Wulff construction. To keep the two contributions to the interfacial energy clear in the rest of the paper, the former is called misfit energy and the latter interfacial-binding energy.

The plate-shaped $\mathrm{Mn}_{3} \mathrm{O}_{4}$ precipitates complying to a minimum misfit energy (i.e. a minimum misfit dislocation density) were not observed in either $\mathrm{Ag}$ or $\mathrm{Cu}$ [4-7]. Apparently in establishing the shape of the precipitate in these systems, the anisotropy in interfacial-binding energy seems to be more important than the anisotropy in misfit energy. Arguments for the strong preference for parallel $\{111\}$ type interfaces compared to parallel (002) interfaces were already given. In fact, combining misfit and interfacial-binding energy, (002) truncated octahedrons are expected. In $\mathrm{Ag}$ after internal oxidation only a small fraction (i.e. less than 1\%) of the precipitates showed large (002) facets, whereas the rest showed no observable truncation. One should realize that Pd is substantially stiffer than $\mathrm{Ag}$. The shear modulus of $\mathrm{Pd}(53.2 \mathrm{GPa})$ is almost a factor 1.6 times larger than that of $\mathrm{Ag}(33.8 \mathrm{GPa})$ and it approaches the stiffness of $\mathrm{MnO}(68 \mathrm{GPa})$. These elastic constants affect the values of the interface dislocation energy factor, i.e. the misfit energy, to a large extent. The elastic energy per unit length of the interface dislocation is given by (Einstein convention):

$$
E=\frac{1}{4 \pi i} \sum_{\eta} \frac{L_{r \eta} L_{s \eta} b_{r} b_{s}}{A_{m \eta \eta} L_{m \eta}} \ln \left(\frac{R}{r_{c}}\right)
$$

The pre-logarithmic factor, i.e. the so-called energy factor $\mathrm{K}$, for heterophase interface depends, in contrast to a homophase interface (grain-bound- 
ary), directly on the various elastic constants and also indirectly via the magnitude of the Burgers vector b. $L_{\mathrm{ij}}$ and $A_{\mathrm{kl}}$ correspond to Lekhnitskii's representation that is valid for the general anisotropic case [8], which are basically the very same vectors as introduced by Stroh [9]. Taking into account the constraints on the continuities in displacements and tractions, the distribution of the Burgers vector in the absence of external forces and the pre-logarithmic factors can be calculated explicitly for $\frac{1}{2}\langle 110\rangle$ interface dislocations on $\{100\}$ and $\{111\}$ planes $[10,11]$. The results are listed in Table I using the elastic constants of $\mathrm{MnO}$. A larger difference in Burgers vector distribution appears for the $\mathrm{Ag} / \mathrm{MnO}$ system because $\mathrm{Ag}$ is the more compliant material. The pre-logarithmic factors for $\frac{1}{2}\langle 110\rangle$ interface dislocations on $\{100\}$ and $\{111\}$ planes in the $\mathrm{Pd} / \mathrm{MnO}$ system are also larger than those in the $\mathrm{Ag} / \mathrm{MnO}$ system. These values are employed to calculate the interface energy (i.e. only the misfit-energy part) due to non-interacting interface dislocations as a function of the isotropic misfit for $\mathrm{Pd} / \mathrm{MnO}$ and $\mathrm{Ag} / \mathrm{MnO}$. The interface energy for $\frac{1}{2}(110)$ interface dislocations in $\mathrm{Pd} / \mathrm{MnO}$ is always larger than in $\mathrm{Ag} / \mathrm{MnO}$, for either $\{100\}$ or $\{111\}$ interface planes. Although in this section $\mathrm{MnO}$ is used instead of $\mathrm{Mn}_{3} \mathrm{O}_{4}$, the calculations are certainly useful to draw the following conclusion about interfaces between $\mathrm{Mn}_{3} \mathrm{O}_{4}$ and either $\mathrm{Pd}$ or $\mathrm{Ag}$. Because of the higher pre-logarithmic factors of $\mathrm{Pd}$, the extra dislocations needed to relieve the larger misfit at the $\{111\}$ compared to the (002) type interface will cost more energy in the Pd than in the Ag system. Hence, in the Pd system the (002)-type interfaces become relatively more stable, explaining the increased (002) truncation of the octahedrons and the presence of the plateshaped precipitates.

Although we treated in this discussion the misfit and the interfacial-binding energy separately, the bonding across the interface is essential to generate the dislocation networks associated with the misfit energy. Based on a comparative study $[10,11]$ between an anisotropic elasticity and an atomistic approach we concluded that the elasticity curve connects points

TABLE I Pre-logarithmic energy factors $\mathrm{K}(\mathrm{eV} / \mathrm{nm})$ and fractions of the Burgers vector for $\frac{1}{2}\langle 100\rangle$ dislocations at $\{100\}$ and $\{111\}$ interfaces between $\mathrm{Pd} / \mathrm{MnO}$ and $\mathrm{Ag} / \mathrm{MnO}$

\begin{tabular}{ccccc}
\hline & $K(\mathrm{eV} / \mathrm{nm})\{100\}$ & $K(\mathrm{eV} / \mathrm{nm})\{\mathrm{lll}\}$ & Fraction $b$ in metal & Fraction $b$ in oxide \\
\hline $\mathrm{Pd}$ & 3.48 & 3.32 & 0.55 & 0.45 \\
$\mathrm{Ag}$ & 2.92 & 2.72 & 0.66 & 0.34 \\
\hline
\end{tabular}


with different interaction parameters (specifying the bonding strength across the interface), that is to say with a higher value at higher misfit. It means that at higher values of mismatch it takes a larger interaction to arrive at dislocation-like structures. Indeed, the $\mathrm{Pd}-\mathrm{O}$ bond strength is higher than the $\mathrm{Ag}-\mathrm{O}$ bond strength and as a consequence the coupling strength across the $\mathrm{Pd} / \mathrm{Mn}_{3} \mathrm{O}_{4}$ interface is high enough to generate interface dislocations on both the $\{111\}$ and (002) interfaces. The electronic bonding due to $2 \mathrm{sp}-\mathrm{O} / 4 \mathrm{~d}-\mathrm{Pd}$ hybridization of $\mathrm{Pd}-\mathrm{O}$ is not available for $\mathrm{Ag}-\mathrm{O}$ and a weaker bond will be formed. The consequence is that the (unreconstructed) polar $\{111\}$ surface of the oxide, which has a dipole in the repeat unit perpendicular to the interface giving rise to a diverging surface energy [12], is stabilized more strongly by $\mathrm{Pd}$ and less by $\mathrm{Ag}$.

So, the general conclusion of the present analysis is (i) anisotropy in interfacial-binding energy for oxide precipitates in a metal matrix is substantial due to the ionic nature of the oxide, giving well defined shapes associated with the Wulff construction, i.e. parallel $\{111\}$ interfaces for $\mathrm{NaCl}$-type oxides in an fce metal matrix, (ii) the influence of misfit on the precipitate shape as bounded by semi-coherent interfaces is important only if sufficient anisotropy in mismatch is present and if the matrix is sufficiently stiff. For a soft matrix (exemplified by $\mathrm{Ag}$ ) the influence of mismatch is hardly present, despite a strong anisotropy in mismatch, whereas for a relatively stiff metal like Pd the strain energy becomes similar in magnitude to the interfacial energy.

\section{References}

[1] Sutton, A.P. and Balluffi, R.W. (1996) Interfaces in Cinstalline Materials, Oxford University Press. New York.

[2] Wulff, G. (1901) Z. Kristallogr: 34. 449.

[3] Iohnson, C.A. and Chakarian, G.D. (1965) J. Meth. Phys. 6, 1403.

[4] Kooi, B.I. Groen, H.B. and De Hosson, JTh.M. (1997) Acta Mater: 45, 3587.

[5] Kooi, B.J., Groen. H.B. and De Hosson, J.Th.M. (1998). Acta Mater: 46, 111.

[6] De Hosson. J.Th.M.. Groen, H.B.. Kooi, B.J. and Vitek, V. (1999) f(ta Mater: 47, 4077.

[7] Kooi, B.J. and De Hosson, J.Th.M. (1998) Acta Mater: 46. 1909.

[8] Lekhunitskii, S.K. (1977) Theory' of Elasficity of an Anisotropic Body, Englisls translation. Holden Day, San Francisco.

[9] Stroh. A.N. (1962) J. Moth. Phis., 41, 77.

[10] De Hosson, I.Th.M.. Groen, H.B., Kooi, B.J. and Vellinga. W.P. (1999) Metal-ceramic interfaces studied with high-resolution transmission miconscropy. In: Adrances in Electronmicroscop!: Ed. U. Valdre, Kluwer, p. 135-160.

[11] Vellinga, W.P.. De Hosson. I.Th.M. and Vitek, V. (1997) Acta Materialia. 45, 1525

[12] Tasker, P.W. (1979) J. Phis. C, 12, 4977. 